\title{
Hegel actual. \\ La paciencia de lo negativo, Gerardo Ávalos Tenorio
}

Pablo Tepichín

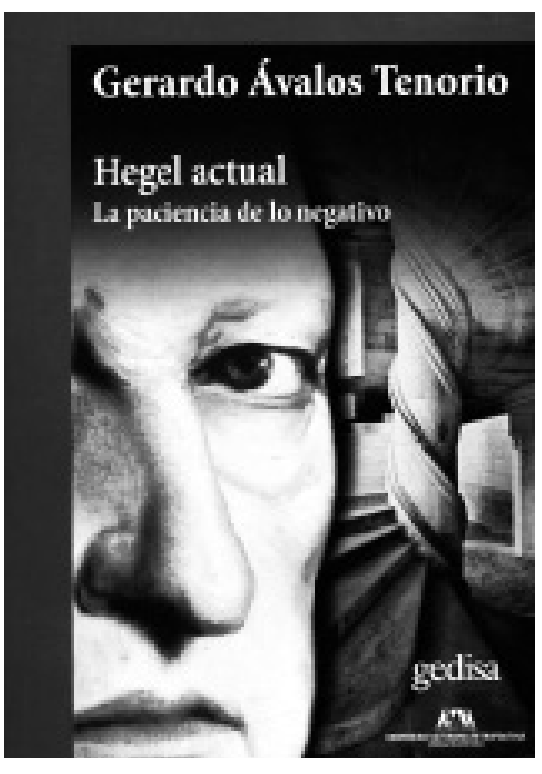

Gerardo Ávalos Tenorio, Hegel actual. La paciencia de lo negativo. Ciudad de México: Gedisa / UAM-X, 2018.
En un contexto mundial de cristalización de discursos hegemónicos que conviven con la exclamación de particularidades, la afirmación del individualismo frente a la comunidad, nuevas formas de consumo amable frente a la fría tecnificación de la producción, la aceleración superyoica como propulsión del imaginario depredador del capital, la corrección pedagógica como nueva forma aséptica y pseudodialogada de dirimir el disenso, el libro Hegel actual. La paciencia de lo negativo de Gerardo Ávalos Tenorio constituye una oportunidad para reorganizar el pensamiento y apretar hasta al fondo el freno de emergencia de la teoría, para detenernos a pensar sobre un huracán llamado presente. 
Desde el inicio de su itinerario, el profesor Ávalos es consciente y deja en claro que el pensamiento de $\mathrm{He}$ gel no sólo es sumamente complejo, sino que "hasta hoy es un territorio de permanente conflicto, al grado de que las diferentes ideologías y posiciones políticas pueden ser comprendidas en función de la idea, noción o interpretación que cada una de ellas haga" ${ }^{1} \mathrm{del}$ filósofo alemán. En ese sentido, reflexiona Ávalos "es que no hay ni puede haber una interpretación definitiva, pero al mismo tiempo eso significa también que la lectura de las obras de Hegel puede inspirar leer nuestro tiempo de una manera creativa, fructífera y novedosa". ${ }^{2}$

Aclarado este aspecto, entre los objetivos que se propone Ávalos Tenorio en el libro está discutir la pertinencia de Hegel, con un desafío intelectual en suma destacable, a saber, explorar las contradicciones de nuestra conflictiva época y las narrativas que las sostienen, con ciertas directrices que permitirían explicar un devenir histórico colmado de aporías, apariencias y de negatividad, esta última, a la que el autor refiere en el propio contexto de la universalidad de una forma social de organización. En otras palabras, hacernos conscientes de lo que como seres humanos estamos realizando a nivel histórico. Por lo tanto, el objetivo del autor no es "actualizar a Hegel”, como podría leerlo alguien mal intencionado o que se quede con la impresión del título del libro; es, antes bien, explorar el complejo pensamiento del filósofo de Stuttgart nacido en 1770 , desde la visión de una época quebradiza. Hegel actual no es una colección de conceptos fríos actualizados al presente, sino una obra imprescindible para comprender el modo en que se desenvuelve nuestra socialidad conflictiva — nuestro estar en el mundoarticulada por la dinámica del espíritu. Así lo explica el profesor-investigador de la Universidad Autónoma Metropolitana-unidad Xochimilco:

Gerardo Ávalos Tenorio, Hegel actual. La paciencia de lo negativo (Ciudad de México: Gedisa/ UAM-X, 2018), 91.

2 Ávalos Tenorio, Hegel actual, 91. 
Digo que un filósofo que propuso una lógica peculiar para pensar la dinámica de los fenómenos que se afirman a través de la negación tiene mucho que decirnos en la época actual en la que se están desmoronando una serie de conciliaciones entre los seres humanos que habían prevalecido todavía en el pasado reciente; armonizaciones entre el capital y el trabajo, y ensambles que le dieron un sentido de racionalidad a la existencia y acción del Estado, devenido Estado social, que hoy en día está siendo socavado por el interés privado ilimitado. ${ }^{3}$

En esta entrega, Gerardo Ávalos reflexiona sobre varios temas: la fenomenología de lo político, el Estado como contradicción, la Revolución y el liberalismo, desde un riguroso tratamiento de las categorías y conceptos hegelianos que, a lo largo de los ocho capítulos del libro, revelan el amplio conocimiento de Ávalos sobre las ciencias sociales en general, y de la filosofía política en particular. La forma en que se desdobla su itinerario se explica con la analogía de pelar una cebolla, donde poco a poco va despojando las capas más inmediatas y superficiales, las cuales serían las que componen aquellos mitos, equívocos o francas tergiversaciones en torno a Hegel, para luego profundizar en la propia espiral de su pensamiento y detenerse a dialogar con el filósofo contemporáneo Charles Taylor. En este apartado, Ávalos se va de lleno sobre uno de los temas que ha atravesado durante años su preocupación teórica, ni más ni menos que la conciliación entre individuo y comunidad, la idea hegeliana de eticidad (Sittlichkeit), y la realidad efectiva de la idea ética, es decir, del Estado y la intersubjetividad, entendida no como yuxtaposición de unos y otros, sino al actuar con el otro, en tanto persona, como un fin en sí mismo.

En esta estación, ya no es posible comprender la formulación procesual tanto de la realidad como certeza sen- 
sible (en alemán, Realität) y de la realidad efectiva, la cual no es otra que la construida por el pensamiento (en alemán, Wirklichkeit), si no se aprecia lo que el mismo Ávalos enfatiza, a saber, que todo el proceso y despliegue del Estado como comunidad está movido por la fuerza de lo negativo en una lógica de superación (Aufhebung). Ya desde antes, en un libro dedicado a una introducción al pensamiento de Hegel, Ávalos afirma que lo negativo es "lo peculiar de la propuesta hegeliana, aquello que lo distingue y separa de sus predecesores, y de las formas filosóficas anteriores". ${ }^{4}$ Es conocida la referencia en la Fenomenología del espíritu a la que Ávalos regresa dialécticamente: "El espíritu sólo conquista su verdad cuando es capaz de encontrarse a sí mismo en el absoluto desgarramiento. El espíritu no es esa potencia como lo positivo que se aparta de lo negativo [...] sino que sólo es esta potencia cuando mira cara a cara a lo negativo y permanece cerca de él". 5 En este sentido, la "paciencia de lo negativo" está muy lejos de ser un recurso estilístico o un adorno literario, antes bien, lo negativo constituye la posibilidad de "una filosofía que mantiene en la tensión permanente que implica incorporar lo negativo como un poder que, a un tiempo, desmiembra lo que aparece firme y fijo y lo reconstituye" ${ }^{6}$ En la analogía de la cebolla que aquí persigo, lo negativo sería lo más cercano al núcleo principal de la filosofía hegeliana $y$, al mismo tiempo, su implacable fuerza centrífuga.

Colocado en el eje de rotación de lo negativo, lo que le ha permitido, entre muchas otras cosas, consolidarse pacientemente como uno de los pensadores de lo político más importantes de nuestro país, es que desde ahí, Ávalos ha sabido añadir a la filosofía, su riguroso conocimiento de la política y del Estado, o en términos filosóficos, entiende que el espíritu significa todo lo humano que hace a la historia y la comprende. Ese devenir del espíritu,

Gerardo Ávalos Tenorio, Breve introducción al pensamiento de Hegel (Ciudad de México: UAm-Xochimilco, 2011), 91.

Ávalos Tenorio, Breve introducción al pensamiento de Hegel, 92.

Ávalos Tenorio, Breve introducción al pensamiento de Hegel, 93. 
explica Ávalos, "está lejos de ser pacífico y armonioso, sino que avanza por conflictos y contradicciones, guerras y revoluciones, terror y muerte"?

En efecto, si hay algo que marca el actual espíritu de los tiempos es nuestra eticidad desgarrada, la proliferación homogeneizadora de narrativas edificantes que ensalzan el individualismo posesivo, la subsunción de lo político y con ello el ocultamiento del desacuerdo por parte de ámbitos privados o de prácticas liberales, que piensan la política en términos de competencia y productos del mercado. En este contexto, Ávalos señala ciertas narrativas del presente, correlacionadas con la temática hegeliana desde la cual se podría vislumbrar una respuesta, por ejemplo: la mundialización, la filosofía de la historia, el discurso neoliberal, la posición que contrarresta la subordinación del Estado a los intereses privados, la rehabilitación de Kant, la teoría de la justicia de Rawls, la ética del discurso de Habermas y Apel, el republicanismo de Hannah Arendt, los intentos de "kantianizar" a Hegel: comprensión de la superación hegeliana de la "mera moral" kantiana, y el "giro" de los cultural studies, el poscolonialismo, los subalternal studies, el multiculturalismo, la interculturalidad y lo decolonial: comprensión de la forma imperial en tanto cultura. ${ }^{8}$

Destaco dos de estos puntos que me parecen importantes por tratarse de la propuesta epistemológica que ha difundido el doctor Ávalos en publicaciones y conferencias recientes. Primero, el énfasis en recordar que en el periodo de Jena, Hegel culmina con la Fenomenología del espiritu, con ello se desprende del formalismo kantiano y elabora el concepto fundamental de Sittlichkeit que se convertirá en el camino de la construcción de su teoría del Estado. En todo caso, no es casual que haya un revival kantiano justo cuando proliferan discursos más allá de las soberanías que ensalzan los derechos humanos; pero también 
asistimos a la imposibilidad más trágica de su cumplimiento, o incluso, una descafeinada acción comunicativa en la cual, desde el inicio del diálogo, uno ya impuso sus propios códigos de comunicación como los únicos deseables, válidos y no negociables.

El segundo aspecto es destacar que Hegel fue crítico del formalismo y del individualismo, los cuales son referentes del pathos liberal dominante el cual, a juicio de Ávalos, pone al alemán en una posición recuperable a través de su idea del fin de la historia. A Hegel se le edulcora para demostrar que el capitalismo y la democracia apuntan los rasgos característicos del "fin de la historia" a la Fukuyama, pero no se señalan las contradicciones del individualismo posesivo, la exclusión social, el despojo, como tampoco la propia negación de la democracia. Frente a estos intentos, Hegel, afirma Ávalos:

nos proporciona la posibilidad de comprender la naturaleza contradictoria del poder, la política y el Estado, lo cual significa asumir la concepción según la cual no puede existir un Estado democrático sin que sea, al mismo tiempo y por su lógica inmanente, un Estado autocrático y no puede haber un Estado de derecho (república) sin que sea, simultáneamente, un Estado de excepción.?

La lucha por el reconocimiento, el problema de la tragedia de Antígona, el alma bella desventurada, el Estado como contradicción y la dimensión religiosa de la vida estatal son otras de las referencias hegelianas que componen este libro, con acento en la idea del universal concreto, en el tiempo especulativo, el entendimiento y la Bildung. Mediante estas coordenadas, el autor nos propone fundamentalmente pensar el presente y el pasado que es presente, tarea, precisamente, de la filosofía.

Celebro la coedición de Hegel actual. La paciencia de lo negativo, la cual se suma a la cuidadosa y extensa bibliografía que Gedisa y el Departamento de Relaciones Sociales de la 
UAM-Xochimilco se han dedicado a difundir en los últimos años. Constituye un imponente esfuerzo teórico, lejos del dogmatismo epistemológico, una obra que pertenece a la comunidad universal del pensamiento, y en ésta, con sus contradicciones y desafíos, es que Ávalos nos invita a releer a un clásico, posicionándonos con y contra Hegel.

Finalmente, el búho de Gerardo levanta el vuelo en el crepúsculo. Muchos de nosotros apenas lo veremos planear en la aurora, mientras, él, en la cornisa, se conserva como el más paciente de los hegelianos. 